\title{
Essential foundations for establishing equivalence in cross-national higher education assessment
}

\section{Sarah Richardson}

Australian Council for Educational Research

University of Melbourne

Higher Education Research

Australian Council for Educational Research

19 Prospect Hill Road

Camberwell

VIC 3124

Australia

School of Social and Political Sciences

University of Melbourne

VIC 3010

Australia

sarah.richardson@acer.edu.au

Tel: +61 (0)3 92775763

Fax: +61 (0)392775500

\section{Hamish Coates}

University of Melbourne

Centre for the Study of Higher Education

University of Melbourne

VIC 3010

Australia

*Corresponding author

\section{Acknowledgments}

The authors acknowledge the Organisation for Economic Cooperation and Development and recognise its ownership of all data, deliverables and instruments produced during the AHELO Feasibility Study.

The authors would like to thank Dr Karine Tremblay of the OECD, Dr Daniel Edwards of the Australian Council for Educational Research and two anonymous reviewers for their comments on an earlier draft of this paper.

\section{Abstract}

The global context of contemporary higher education demands international benchmarks. Quality assurance of teaching and learning would benefit from the insights gained from cross-cultural assessments. If cross-cultural assessments are used it is imperative that equivalence is assured, requiring attention to the technical standards used. In this paper we draw on our experiences implementing the OECD's Assessment of Higher Education Learning Outcomes (AHELO) Feasibility Study across 17 countries. We consider the key standards required in a number of core technical areas to achieve equivalence. We discuss how different elements were achieved in the AHELO study. These include the development of assessment materials for use across languages; selection and engagement of students; delivery of assessment materials and analysis of assessment data. 
Keywords

Learning outcomes; cross-national; Assessment; Quality assurance; equivalency

\subsection{Introduction}

Cross-national assessment in higher education is at an embryonic stage. Unlike the schools sector, higher education institutions do not have decades of international comparative assessments to inform practice. Indeed, efforts to improve system policy, institutional strategy and education quality suffer from a substantial information gap. There is very little reliable information to enable comparative judgments to be made about the capabilities of students in different institutions and in different national and regional systems, or about the quality of teaching.

This situation is increasingly untenable given the increasingly global contexts shaping higher education. In the absence of rigorous data on teaching and learning stakeholders rely on researchfocused and reputational rankings. These rankings distort decision-making by individuals, institutions and governments. They imply that institutions which excel in research equally excel in teaching and learning, a connection which is difficult to establish (Hattie and Marsh 1996). Additional information on learning is required. In response, the Organisation for Economic Cooperation and Development (OECD) conducted the Assessment of Higher Education Learning Outcomes (AHELO) Feasibility Study between 2010 and 2012.

The AHELO Feasibility Study was a landmark international higher education assessment development. Its remit, scope and intent were pioneering in many ways. It built on significant advances in efforts to map, categorise and define higher education outcomes (Tuning Association 2011; U-Map 2013; Van Vught and Ziegele 2012). These initiatives have focused greater attention on the educational function of higher institutions but have not included the provision of data on the outcomes of teaching and learning. The aim of the AHELO Feasibility Study was to fill this gap, developing and implementing a rigorous data collection on higher education student learning outcomes which enabled comparisons across national and regional systems, languages and institutions.

The AHELO Feasibility Study demonstrated that a successful cross-national study that produces cogent data on student learning is built on a host of interconnected activities. Key to demonstrating feasibility in the AHELO Feasibility Study was the achievement of international agreement regarding assessment and contextual frameworks and instruments. Beyond this, it was essential to ensure that translation processes resulted in assessment instruments with equivalency across languages. Institutions and students had to be engaged and student populations accurately identified and sampled. Online deployment of instrumentation needed to work smoothly across a range of institutional, cultural and linguistic contexts. Data required accurate cleaning, analysis and reporting to generate valid results. Deviations in the implementation of any one of these would have undermined equivalence in the data collected.

Each of the steps and processes identified here were complex and technically advanced. Lessons learned from decades of cross-national studies in the primary and secondary sectors were applied to the higher education sector for the first time. In this paper we contribute to the development of future cross-national assessments. We draw on the management and implementation of the AHELO Feasibility Study to provide high level analysis of the interplay of all of the parts. With an emphasis on methodology, we consider the threshold standards necessary to have confidence in future crossnational assessments. We look at the capacity which is essential in determining the readiness of participating countries and institutions. 
As we conclude, the contemporary higher education context is one which is ripe for the application of new insights to innovative assessment. Demands for transparency and the demonstration of quality are coming from a range of stakeholders. Governments want assurance that their funding is well directed. Societies need to know that higher education institutions are producing informed citizens. Employers want to know that graduates are equipped with relevant knowledge and skills which not only enable them to meet local demands but also to respond to global contexts. Students and parents want evidence that institutions are able to facilitate the learning demanded by a significant investment of time and money. Global imperatives call for international cooperation and comparison. Cross-national assessments offer significant benefits for higher education institutions. These are yet to be optimised and we predict that the AHELO Feasibility Study marks the beginning of a new era.

\subsection{Background—rationale and structure of the AHELO Feasibility Study}

The AHELO Feasibility Study constituted a multinational data collection effort in higher education. It involved 23000 students in the final year of their bachelor level degrees at 250 higher education institutions in 17 countries across the Americas, Asia, Europe and the Middle East. The higher education institutions which participated varied immensely, ranging from large research intensive institutions ranked in the top 100 in the world to small teaching only institutions. Other variations included institutional mission (teaching, research or balanced focus), level of students taught (undergraduate only or undergraduate and postgraduate), funding source (public, private or mixed), fields of education taught, curriculum structure, selectivity and retention of students, types of students enrolled and number and type of faculty.

The AHELO Feasibility Study arose from a number of initiatives to address the paucity of information on higher education performance. While each one has considerable merit, they have all been limited in scope. Rankings address some elements of higher education performance but tend to focus on research at the expense of teaching and learning (van Vught 2010). Competency based approaches (Tuning Association 2011) frame competencies as outcomes that graduates are expected to have but do not measure their achievement. National qualification frameworks have become policy instruments which often underemphasise their specific contexts (McBride and Keevy 2010). Measures of student engagement such as the United States National Survey of Student Engagement (NSSE 2012) can only deliver proxy information on student learning.

In this context the AHELO Feasibility Study was established to focus attention on students' learning outcomes as a key factor of institutional performance (Coates and Richardson 2011). It came about at a time when there is an emerging realisation of the shortcomings of traditional approaches to higher education assessment. The ubiquity of academic staff members at an individual institution writing examinations, assessing student responses and then providing students with grades is increasingly being questioned (Falchikov 2005; G Kuh and Ewell 2010). Ideally, local assessment is complemented by broader forms of external assessment. This approach allows institutions to balance two requirements. First, their need to respond to specific demands driven by the local contexts in which many graduates are likely to commence employment. Second, their desire to gain valid, reliable and relevant data on student learning that can be used for benchmarking and continuous improvement.

Generalisable assessment can be local. This includes the use of common examinations or shared item libraries (Australian Medical School Collaboration 2013; Edwards et al. 2013). But by expanding generalisable assessment to the international level, the reality of a globally competitive marketplace for higher education graduates, and hence the need for benchmarks which transcend national borders, is acknowledged. Higher education systems can gain information to support diversification, to evaluate accountability systems and to monitor the performance and contribution of higher education. Teaching staff are included in designing and evaluating assessment materials with colleagues from around the world, and using evaluation data to transform policy and practice. Students are engaged in the global world of knowledge, providing them with international perspectives on the standard and scope of achievement. 
All of these benefits point to the value inherent in cross-national studies of student skills and knowledge through assessment. Understanding this imperative is one thing. Implementing a crossnational assessment is quite another. The focus of the AHELO Feasibility Study was not only to achieve the goals of developing and implementing assessment instruments. An equal focus was on positioning AHELO in ways that provided robust foundations for future cross-national assessments. Establishing and maintaining equivalence were central to all activities.

In most participating countries it was not difficult to find higher education institutions which were eager to participate in the AHELO Feasibility Study. When surveyed, participating institutions were also keen to be involved in a potential AHELO Main Study (Brese and Daniel 2012). The demand to participate despite the cutting-edge nature and uncertain outcomes of the Feasibility Study is reflective of a pressing need among institutions, a need which is not currently being met. In the same way that students are eager to know how their performance measures up against others in their cohort, institutions are hungry for information on how they are performing in relation to their peers.

Ranks of institutions based on how their students participated would have been straightforward to produce but this was not the emphasis in the AHELO Feasibility Study. Instead, considerable efforts were made to use a contextual lens to understand student achievement, taking into account the variety of ways in which students, teaching staff and leaders engage in an increasingly diverse and higher education environment (G. Kuh and Ikenberry 2009; Marginson and van der Wende 2007; van Vught 2009). Thus the goal was to supply institutions with nuanced insights into student performance which could inform improvements in teaching and learning.

In the sections below we consider the key technical standards and design features used for a number of core activities in the AHELO Feasibility Study. These include ensuring that assessment materials were suitable for use in different countries and using targeted analyses to ensure that assessment items which demonstrated bias were removed from overall reporting. We highlight key considerations which underscored each aspect. For future cross-national higher education assessments the AHELO Feasibility Study provides a valuable resource on how to achieve each of these discrete elements. While AHELO focuses on the measurement of learning outcomes in higher education institutions, insights are equally applicable to all forms of assessment at the higher education level. Extensive details about the technical designs used in AHELO can be found in a series of AHELO documents available from the OECD's AHELO webpage (http://www.oecd.org/edu/skills-beyondschool/ahelodocuments.htm) and from the three volumes of the AHELO Feasibility Study Report (Organisation for Economic Cooperation and Development 2012, 2013a, 2013b).

\subsection{Development of cross-national assessment materials}

In the higher education sector it is common practice for student knowledge and skill to be measured using un-calibrated tasks that are scored normatively using un-standardised rubrics and then, frequently with minimal moderation, adjusted to fit prescribed percentile distributions. This may be deemed acceptable in highly localised contexts but is not appropriate for cross-national higher education assessments. Thus the development of the AHELO Feasibility Study needed to ensure high quality in all components - task development, scoring procedures, rubrics and reporting.

The first stage in any assessment is to determine what is to be measured, the purpose of doing so and to develop assessment instrumentation to achieve this objective. Whether the intention is to measure skills and competencies in specific domain areas or to develop an assessment for the measurement of generic skills across disciplines, a number of key elements are required. First, a representative group of domain experts establishes the parameters of the domain to be assessed. Second, instrumentation is created which maps to the agreed definition and enables assessment objectives to be achieved. Third, draft assessment material is validated via qualitative and/or pilot testing of the assessment instrument and revised accordingly. Each step is critical in ensuring that the assessment materials are valid and reliable. 
In a cross-national assessment it must be assumed that curricula and learning objectives are not uniform. It is possible to take materials which have been developed for use in just one jurisdiction and apply them to others but this approach may result in cultural bias which could invalidate results. The alternative approach is to establish international expert groups to assist with assessment development. The latter approach was used in the AHELO Feasibility Study to develop economics and engineering assessment frameworks and instruments. Expert group members were senior assessment and disciplinary experts in relevant domains from a number of countries. Their role was to consider variations in higher education practices, curriculum structures and expected outcomes and to develop an assessment framework which defined a domain applicable to all.

The assessment frameworks which expert groups developed were the scaffolding around which assessment instrumentation was developed. Assessment frameworks are routinely omitted in much higher education assessment but are an essential step in the development of rigorous and valid assessment materials. Assessment frameworks provide a technical and theoretical base on which educational achievement can be investigated, reported and discussed. They make the link between assessment outcomes and educational practice. They establish the context of the domain and provide an organisational structure for it. In illustration, the domain for the engineering strand of the AHELO Feasibility Study was defined in the AHELO Engineering Assessment Framework as follows:

First-cycle Engineering competency is the demonstrated capacity to solve problems by applying basic Engineering and scientific principles, Engineering processes and generic skills. It includes the willingness to engage with such problems in order to improve the quality of life, address social needs, and improve the competitiveness and commercial success of society (Australian Council for Educational Research et al. 2011).

In the AHELO Feasibility Study both pre-existing and newly developed materials were used. All assessment materials were mapped to assessment frameworks. Draft materials were then subject to testing by end-users, in this case students and teaching staff, during focus groups. In large scale assessment the pilot testing of assessment materials is a vital stage but this was not included in the AHELO Feasibility Study as its emphasis was to test the practical feasibility of implementing an AHELO rather than prepare instrumentation for use in future assessments. In other cross-national higher education assessment exercises, it would be necessary to organise a full field trial.

\subsection{Preparation for cross-national assessment}

Readying assessment material for implementation to students demands a number of quality procedures. These aim to ensure that all assessment materials presented to students are fully fit for purpose. In cross-national assessments the complexity and number of these procedures is inevitably increased as it is likely that assessment materials need to be prepared for use in a number of languages. In this situation it is imperative to maintain cross-language equivalence. This means that "each item should examine the same skills and invoke the same cognitive processes as the original version, while being culturally appropriate within the target country" (Australian Council for Educational Research et al. 2012). Materials in the AHELO Feasibility Study were translated into 12 languages and the approach used contains important lessons for future cross-national assessments.

Rigorous localisation involves a detailed process of translation, adaptation and verification. Translation involved the creation of two translations which were then reconciled. Domain-specialists from each cultural context were employed to analyse each word and phrase for accuracy, ensuring that jargon and technical terms were appropriately translated. Even when instruments in the same 'language' are used it is necessary to ensure that each version is the best fit for the local context. Thus in the AHELO Feasibility Study the engineering instrument was used in English in Abu Dhabi, Australia, Canada and Egypt, but not all versions were identical due to adaptation to fit local contexts, including variations in terminology and spelling. 
To enhance reporting, contextual instruments for students, teaching staff and institutions were developed. Instruments drew on the approaches taken in other studies such as NSSE and U-Map (NSSE 2012; van Vught 2009) and encompassed a range of aspects of institutional and teaching characteristics as well as student educational experiences. Each contextual instrument went through the same rigorous process of localisation as assessment instruments. This was vital in ensuring that equivalent contextual information was collected from across institutions. To account for local diversity each country was able to add or delete a limited number of elements as appropriate.

Verification of population counts and the selection of students is another essential quality procedure in large scale assessment. The accuracy of population counts plays a critical role in ensuring the quality and generalisability of estimates, and hence the comparability and validity of results. In crossnational studies like AHELO the successful application of probabilistic sampling methods at the institutional level is essential for ensuring equivalence (Statistics Canada 2011). This requires participating institutions to supply detailed and accurate student unit records, something which the AHELO Feasibility Study demonstrated is not possible for all institutions.

Low response rates undermine the validity of data collected and can jeopardize all the effort put into developing rigorous assessments. In post-compulsory education it is difficult to compel students to take a low-stakes assessment. Experience in the AHELO Feasibility Study suggests that student engagement is highly culturally specific. In some cultural contexts simply being asked by their institution to participate was enough to motivate students. In other cultural contexts this had little to no impact and other approaches were required. Many institutions used a multi-faceted strategy of student recruitment involving communication and marketing, and a range of inducements and incentives. In some cases participation was made compulsory. A lack of feedback to students on their performance increased the difficultly of student engagement and would need to be reconsidered in future cross-cultural assessment initiatives.

The final element in preparing for cross-national assessment is to determine the delivery mechanism. All student assessment, data collection and marking of student responses in the AHELO Feasibility Study were undertaken online. While highly practical, it did raise a number of challenges. Test sessions took place in hundreds of locations worldwide. Ensuring that technical capacity was sufficient - both within institutions and internationally - was a substantial challenge. Technology had to be robust, reliable and user-friendly and to be able to cope with thousands of simultaneous users in different countries and in different languages. Each unique test login needed to be accurately distributed to one of more than 30000 end users in order to match with population records. Overall, the use of online deployment in the AHELO Feasibility Study was largely successful and the study uncovered a number of considerations that are key to the success of online testing in any future crossnational assessments (Organisation for Economic Cooperation and Development 2012).

\subsection{Analysis and reporting of cross-national assessment data}

Data in the AHELO Feasibility Study were collected to satisfy a number of audiences. Each participating institution received individualised data collected from all students and faculty members at that institution who participated in AHELO, in addition to a tailored report comparing the performance of students at that institution against international benchmarks. Each government received individualised data for all students and teaching staff in their country which had participated. The OECD received a full database of all data collected and this is likely to be used by researchers into the future. Ensuring the accuracy and reliability of highly complex data sets required a number of key steps.

All data in the AHELO Feasibility Study were collected online. Student responses to multiple-choice questions were marked automatically. Contextual data from students, teaching staff members and institutions were collected from both open and closed responses. Open-response data supplied in languages other than English required translation prior to analysis. The most complex data elements were those collected through student responses to constructed response tasks (or 'open questions'). 
Marking, or 'scoring', of students' responses to constructed response tasks was conducted by scoring teams in each participating country. To ensure consistent standards detailed scoring rubrics were prepared for each of the three assessments used in the AHELO Feasibility Study. These provided rubrics for every discrete question, indicating the number of points available and the required student responses for each score point. Rubrics also indicated example student responses.

The sheer number of languages used the AHELO Feasibility Study precluded comparative scoring across countries, although this was done to a limited degree between some countries which tested students in the English language. Translating student responses and then providing them to scorers in other countries were considered but ruled out due to the cost involved and the risk of introducing translation error variation into response data. Instead, the approach used in AHELO drew lessons from approaches used in other large scale international testing (Schulz et al. 2011).

In addition to the use of detailed rubrics, individuals in charge of scoring in each participating country attended two international training sessions. Scorers and assessment developers worked carefully through each rubric to ensure that consistent standards were being applied. They then returned home and trained scoring teams in their countries. During scoring itself (which was almost all conducted online) the quality of scoring was continuously monitored through double scoring and the use of interrater reliability statistics. This allowed the Lead Scorer in each country to take remedial action where one or more scorers deviated from protocols.

The AHELO Feasibility Study indicates that the use of constructed response tasks in cross-national generalisable assessments is valuable. They allow data to be collected on the ability of students to express the challenges, solutions and contingencies involved in a situation. This must be offset by the added time and resources which their inclusion inevitably implies, however. A consideration of technical, operational and substantive criteria is essential in determining how to assess what students know and can do across countries. The goal of the assessment is an equally important criterion. Constructed response tasks provide valuable insights to institutions to inform the improvement of teaching and learning, an important consideration in an endeavour such as AHELO.

All data collected in the AHELO Feasibility Study were prepared in files which were produced to enable linkage across different instruments, and ensure accurate and consistent storage of information. Data cleaning included a number of activities including valid range checks, identification-variable cleaning, between-file linkage checks, cleaning of background inconsistencies and re-arranging the file structure towards data analysis. Data files were validated using univariate and bivariate descriptive statistical analysis and the imputation of non-response codes. Tables with descriptive summaries of all variables were produced for each country or region and institution. Countries were asked to review these summaries and note any objections to data or files, a process which validated the quality of the file build.

Detailed psychometric methodologies were used to scale data collected during the AHELO Feasibility Study. Items were calibrated with two IRT models: the dichotomous Rasch model (Rasch 1980) and the partial credit model (Masters and Keeves 1999). The Rasch model was used for multiple choice questions and dichotomously scored items from constructed responses tasks. Constructed response tasks scored with more than two categories were scaled with the partial credit model (a generalisation of the dichotomous Rasch model). The Rasch model was used because of all available item response theory models it provides the strictest assessment of psychometric validity and supports the construction and validation of meaningfully described proficiency scales for use in cross-national studies.

Modelling took place in three stages. First, national calibrations, in which the scaling was replicated across national contexts to ascertain the stability of item parameter estimates. Second, international calibration, based on full international data or replicated across several subsamples drawn from the international data. Third, individual ability estimate generation, in which plausible values are estimated for each student completing an assessment. Any items that did not perform well 
psychometrically were removed from analysis, either for one country or overall. Removing items where an item-by-country interaction was observed ensured that the instruments were more equivalent across countries.

Once the item deletion process was finalised an international scale was established, and a single student score was generated for each assessment strand. Two different kinds of estimates were produced. First, weighted maximum likelihood estimation scores (Warm 1985) were estimated to facilitate any reporting at the individual level. Second, the imputation methodology referred to as plausible values was used. As in other large scale surveys, five sets of plausible values were drawn. In each assessment strand the estimates and plausible values were transformed into scale scores with a mean of 500 and standard deviation of 100 (Australian Council for Educational Research 2012).

Additional psychometric analyses were also conducted to generate reliability and validity statistics, and test the efficiency of alternate scoring methods. Reliability estimates were produced for the student and institutional levels and are detailed in public reporting on the Feasibility Study (Organisation for Economic Cooperation and Development 2013a). Item response modelling was used to assess the 'targeting' of the assessment to respondent cohorts. This involved checking whether the distribution of item difficulty mapped well against the distribution of respondent capability. The cross-contextual validity of the assessment items was explored by assessing differential item functioning. This indicates whether the probability of successful performance is a function of group membership (such as gender) as well as individual ability. Item fit to the measurement dimension was assessed using a range of item statistics. Unplanned item-level non-response was analysed to identify response patterns. The generalisability of constructed response task data across national and linguistic contexts as well as institutional types was examined.

Each participating institution received a report in which results of their student cohort were compared with international benchmarks. Comparisons were made against both international means and also means obtained by student cohorts both with specific characteristics and also attending institutions with defined remits and identities. No student level results were reported as the AHELO assessments were designed to yield information at the institutional level. Nevertheless a strong demand from stakeholders for discrete results for participating students does indicate that providing students with an immediate indication of performance on completion of the assessment should be considered in future cross-national studies. Dynamic forms of online reporting were not within the scope of the AHELO Feasibility Study but hold great potential for future cross-national studies. Examples include U-MAP (van Vught 2009), the CHE Ranking (Centrum für Hochschulentwicklung (CHE) 2009) and the NSSE Report Builder (NSSE 2012).

\subsection{Summary and conclusions}

Learning lies at the heart of higher education. The capacity to deliver quality teaching and learning is something which institutions need to demonstrate to stakeholders. Students need higher education institutions to help them gain the skills and knowledge they will need to commence their careers and to thrive in their careers. Students also need higher education institutions to facilitate their growth into adults with the ability to navigate diverse careers and to contribute to society as informed citizens. Localised approaches to assessment work well in many cases, and enable institutions to ensure that students have the appropriate set of skills and knowledge required by employers in the local context. But in addition to meeting local demands, it is also vital that higher education institutions prepare students for careers and lives that are likely to involve them in a range of contexts, activities and communities. And increasingly many of these will be global.

The AHELO Feasibility Study brought together institutions which are generally autonomous and responsible for governing their own standards and involved them in an independent assessment of learning. It formed a coalition between those interested in assessment and higher education policy by focusing attention on learning outcomes as an important measure of higher education effectiveness. It laid the foundation stones for future cross-national assessments. Done well, cross-national 
assessments can provide institutions with a nuanced understanding of the performance of students against those in other institutions with similar characteristics. For example, performance of students at one institution can be measured against that of students at institutions of a similar size, with a similar mission or with a student cohort with similar characteristics. Data collected from cross-national assessments can guide institutions and teaching staff on ways to enhance teaching and learning. Participation in cross-national assessments can give institutions and teaching staff valuable means of building assessment capacity and leading evidence-based change. International benchmarking of teaching and learning allows institutions to understand their strengths and weaknesses in the international context which their students inhabit. All indications are that cross-national assessment may in coming years become an integral part of higher education quality management.

It is important to remember, however, that cross-national assessments are not designed to replace localised approaches to assessment but to complement them. They enable institutions to compare the learning of students against not only national but also international benchmarks.

Despite the advantages which can be obtained from cross-national assessments it is vital to acknowledge their limitations. By their very nature, cross-national assessments cannot comprehensively measure student achievement in all elements of all curricula at all institutions. The use of groups of experts from around the world to determine what skills and knowledge should be assessed in cross-national assessments demands a focus on common curricula areas. Due to their specific and localised nature, some elements of curricula - perhaps those most vital in local contexts will always need to be excluded. This in no way suggests that specific curricula areas are less important than those which are common across countries. Indeed, it is vital that higher education institutions remain able to respond to local needs as much as those of more general importance. As such, it is important to view cross-national assessments as a valuable addition to the quality improvement tools available to institutions and governments rather than a replacement of other higher education assessment practices. If this important point is borne in mind there is no reason why crossnational assessments should lead to uniformity in curricula.

For cross-national assessments to be effective a rigorous approach is essential. A host of measures are required to ensure that the development, implementation, analysis and reporting used in cross-national assessments are valid, replicable and consistently applied. Cross-national assessments also need to be able to take account of variations between institutions and countries. These include the structure of the higher education sector and the timing of the academic year. In addition, a certain degree of participant readiness is required. Without particular infrastructure and capability in place countries and institutions will struggle to cope with the demands placed upon them and will be unable to adhere to timelines, jeopardising the overall success of the study. In the AHELO Feasibility Study this was mitigated as far as possible by the provision of extensive training, documentation and support to guide National Centres through every step. But it became clear that other requirements are also necessary.

Any country that intends to participate in a cross-national assessment must be able to provide senior representation at international policy and management meetings. Prior experience in cross-national studies, for example at the school level, is extremely beneficial. International representatives need the capacity to spur interest and action within the national system. Funding, infrastructure and policy support is required to coordinate activities through a centralised administration. Project managers should have prior experience in managing relevant studies with a high degree of efficiency and quality. Access to expertise in sampling, translation, IT, scoring, fieldwork management and statistics is essential. Experts in the disciplines being assessed need to be available for international consultation. The ability to maintain confidentiality and security of materials and data is imperative.

Institutions need to appoint a coordinator. This person must have sufficient formal authority to engage leaders, teaching staff and students, and to represent the institution nationally. Knowledge and experience in implementing large-scale educational assessments is valuable. Governance and management arrangements for interpreting and acting on results are very important. On a practical level, robust population specification and student selection is essential, as is appropriate IT 
infrastructure and the capacity to quality assure online assessment. Institutions must also have capacity to recruit and engage students in the assessment process.

With these preconditions in place, and proper attention to all of the technically rigorous activities outlined in this paper, cross-national studies have tremendous potential to enrich the higher education sector around the world. Their ability to provide institutions, governments, employers and students with much-needed insights into the quality of teaching and learning is unparalleled. We anticipate that cross-national assessments will become a commonplace feature of quality assurance in higher education in the coming years.

\section{References}

Australian Council for Educational Research (2012). AHELO Analysis and Reporting Design. Paris: OECD.

Australian Council for Educational Research, Council for Aid to Education, \& cApStAn (2012). AHELO Adaptation, Translation and Verification report. Paris: OECD.

Australian Council for Educational Research, National Institute for Educational Policy Research, \& University of Florence (2011). AHELO Engineering Assessment Framework. Paris: Organisation for Economic Cooperation and Development.

Australian Medical School Collaboration (2013). Australian Medical Assessment collaboration. http://www.acer.edu.au/amac. Accessed 10 May 2013.

Brese, F., \& Daniel, T. (2012). OECD Assessment of Higher Education Learning Outcomes (AHELO) Feasibility Study: Report on Quality Adherence. Hamburg: IEA Data Processing and Research Center.

Centrum für Hochschulentwicklung (CHE) (2009). CHE Ranking. http://www.che.de/cms/. Accessed 8 January 2011.

Coates, H., \& Richardson, S. (2011). An International Assessment of Bachelor Degree Graduates' Learning Outcomes. Higher Education Management and Policy, 23(3), 1-19.

Edwards, D., Wilkinson, D., Canny, B., Pearce, J., \& Coates, H. (2013). Developing outcomes assessments for collaborative, cross-institutional benchmarking: Progress of the Australian Medical Assessment Collaboration. Medical Teacher.

Falchikov, N. (2005). Improving assessment through student involvement: practical solutions for aiding learning in higher and further education. Abingdon: RoutledgeFalmer.

Hattie, J., \& Marsh, H. (1996). The relationship between research and teaching: A meta-analysis. Review of Educational Research, 66(4), 507-542.

Kuh, G., \& Ewell, P. (2010). The state of learning outcomes assessment in the United States. Higher Education Management \& Policy, 22(1), 9-28.

Kuh, G., \& Ikenberry, S. (2009). More than you think, Less than we need: learning outcomes assessment in American Higher Education. Urbana, IL: University of Illinois and Indiana University, National Institute for Learning Outcomes Assessment.

Marginson, S., \& van der Wende, M. (2007). Globalization and Higher Education. Education Working Paper No. 8, Directorate of Education, OECD. Paris: OECD. 
Masters, G. N., \& Keeves, J. P. (1999). Advances in measurement in educational research and assessment. New York: Pergamon.

McBride, V., \& Keevy, J. (2010). Is the national qualifications framework a broken promise? A dialogue. Journal of Educational Change, 11(2), 193-203.

NSSE (2012). National Survey of Student Engagement. Indiana University: Center for Postsecondary Research.

Organisation for Economic Cooperation and Development (2012). Assessment of Higher Education Learning Outcomes (AHELO) Feasibility Study Report - Volume 1 Design and Implementation. Paris: Organisation for Economic Cooperation and Development.

Organisation for Economic Cooperation and Development (2013a). Assessment of Higher Education Learning Outcomes (AHELO) Feasibility Study Report - Volume 2 Data Analysis and National Experiences Paris: Organisation for Economic Cooperation and Development.

Organisation for Economic Cooperation and Development (2013b). Assessment of Higher Education Learning Outcomes (AHELO) Feasibility Study Report - Volume 3 Further Insights Paris: Organisation for Economic Cooperation and Development.

Rasch, G. (1980). Probabilistic models for some intelligence and attainment tests. Chicago: The University of Chicago Press.

Schulz, W., Ainley, J., \& Fraillon, J. (2011). ICCS 2009 Technical Report Amsterdam: International Association for the Evaluation of Educational Achievement.

Statistics Canada (2011). AHELO Sampling Manual. Paris: OECD.

Tuning Association (2011). Tuning Educational Structures in Europe www.unideusto.org/tuningeu/home.html. Accessed 25 March 2011.

U-Map (2013). The European Classification of Higher Education Institutions. http://www.u-map.eu/. Accessed 12 February 2013.

van Vught, F. A. (2009). Mapping the Higher Education Landscape: Towards a European Classification of Higher Education. Dordrecht: Springer.

van Vught, F. A. (2010). The Europe of Knowledge. In D. D. Dill, \& F. A. van Vught (Eds.), National Innovation Policies and the Academic Research Enterprise. Baltimore: Johns Hopkins University Press.

Van Vught, F. A., \& Ziegele, F. (2012). Multidimensional Ranking: The Design and Development of U-Multirank (Vol. 37 Higher Education Dynamics). Dordrecht: Springer Netherlands.

Warm, T. A. (1985). Weighted maximum likelihood estimation of ability in Item Response Theory with tests of finite length" Technical Report Oklahoma City: U.S. Coast Guard Institute. 


\section{University Library}

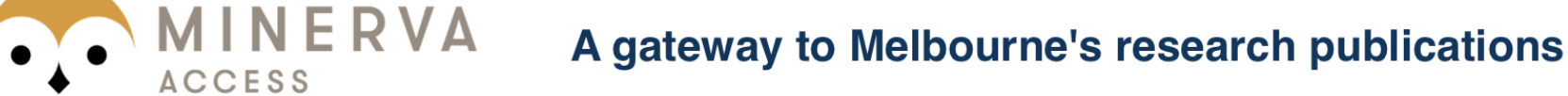

Minerva Access is the Institutional Repository of The University of Melbourne

Author/s:

Richardson, S;Coates, $\mathrm{H}$

Title:

Essential foundations for establishing equivalence in cross-national higher education assessment

Date:

2014-12-01

Citation:

Richardson, S. \& Coates, H. (2014). Essential foundations for establishing equivalence in cross-national higher education assessment. HIGHER EDUCATION, 68 (6), pp.825-836. https://doi.org/10.1007/s10734-014-9746-9.

Persistent Link:

http://hdl.handle.net/11343/283082 